\title{
Validation of a vapour compression refrigeration system design model
}

\author{
M. A. Akintunde \\ Federal University of Technology, Department of Mechanical Engineering, \\ PMB. 704, Akure, Ondo State, Nigeria, +2348.35011797, ajyinka@yahoo.com
}

\begin{abstract}
This paper presents the validation of a design model for vapour compression refrigeration systems developed by Akintunde (2004a). This model was used to design a vapour compression refrigeration system. The experimental set-up is made up of: a compressor- reciprocating type, $0.746 \mathrm{~kW}$ capacity, using R134a as working fluid, with cylinder stoke volume of $32.7 \mathrm{~cm}^{2}$; evaporator and condenser, bare coil tube-in-tube serpentine copper coil. The cycle performance was evaluated through the following parameters; Cooling load (Qe); Condensing load (Qc); Coefficient of performance (COP) and mass flow rate. The $R$ values (calculating using excel) of the COPs under subcooling and superheating with the degree of subcooling and superheating conditions were $80.7 \%$ and $88 \%$ respectively. While the correlations between the COPs under the same conditions were $88 \%$ and $99.9 \%$. The present analysis showed that the model results are comparable to the actual system from both quantitative and qualitative points of view. Under the same operational conditions, maximum absolute deviations of the variable parameters - mass flow rate, COP and circulating water temperature, are within the range of $16 \%$.
\end{abstract}

Keywords: validation, evaluation, COP, alternative, refrigerant,

\section{INTRODUCTION}

The application of vapour compression system cycles, using R-12 and R-22 and other halocarbon compounds, had gone deep in the field of refrigeration and air-conditioning before the advent of ozone depletion. It is a known fact that the working fluids used in refrigeration and air-conditioning systems are to be phased out (Mahmoud et al., 2002; Hafez and Rahman, 1992; Ko et al., 1993). Resulting from the ozone depletion potentials of these working fluids and the consequences effects of the phasing out of these fluids, researchers are focused on identifying alternative working fluids.

Statt (1990) studied potential substitute refrigerants for centrifugal chillers that use R-12. The alternatives were required to have normal boiling points close to that of R-12. He found thirteen (13) compounds that satisfied this criterion. These are: R-115; 500, 502, 505,506 , which are already banned R-161 which is highly toxic; R-143a, 152a which are slightly flammable and R-22, 124, 125, 134 and 134a which are nonflammable. There are many other works published on the alternatives to $\mathrm{R}-12$ and other ozone depletion refrigerants, some of these are: Kutter (1988); Clark, (1999); Eckels and Tesene (2003); Eckels and Tesene (2004); Sand et al., (1990); Crow et al., (1992). It has been concluded by many researchers that - from thermodynamic point of view R-134a is closely related to $R-12$ in most important thermodynamic properties of refrigerants (Bolaji, 2008; Akintunde, 2007; Calm, 2002; Kim et al., 2002).

Although, R-134a is presently been used as one of the best alternatives to R-12, there are still some notable problems. Statt (1990), reported that R-22 and R-134a will decrease both the capacity and efficiency by 5 to $10 \%$. Al-Rabghi (1996), compared the theoretical performance of three candidate substitutes, R-22; R-717 and R-134a, in a one ton refrigeration system $\mathrm{R}-12$ based unit with an evaporating temperature of $10^{\circ} \mathrm{C}$ and $55^{\circ} \mathrm{C}$ condensing temperature. The result showed that $\mathrm{R}$ $134 a$ decreases both the coefficient of performance (COP) and the capacity by $6.0 \%$ and $15.9 \%$ respectively. Veneyard et al., (1989), reported that R$134 a$ had higher energy consumption than R-12 by $7.8 \%$. Due to these discrepancies it was believed that the systems using R-12 should be redesigned to accommodate R-134a.

Kamei et al., (1990); Pannock et al., (1994) and Linton et al., (1992), studied the performance of R$134 a, R-152 a$ and R-12. They concluded that new R134a systems could be designed to outperform the corresponding R-12 systems by the proper addition of subcooling. Linton et al., (1989), tested the performance of R-134a in a residential exhaust air heat pump designed for R-12. The results showed both refrigerants to have about the same heating (i.e. 
output) capacity, evaporating pressure and evaporating and condensing temperatures. R-134a had higher condensing pressure by about $140 \mathrm{kPa}$ and lower COP by about $15 \%$. The expansion valve required much larger orifice to perform satisfactorily in the case of R-134a. Other proofs can be found in the works of Crown et al., (1992); Abu-Madi et al., (1992) and Hel-Haggar et al., (1996).

Akintunde (2004a) and Akintunde (2004b) observed that, the performance of R-134a may be enhanced if the refrigeration systems are redesigned based on thermodynamic properties of the working fluids. He further observed that if balanced points (as suggested by Stoecker and Jones, 1982) between the refrigeration systems components (viz: compressor, condenser, evaporator and expander) are identified and these components can work together at these balanced points then the performance will be improved. $\mathrm{He}$ therefore developed a model based on both the balanced points between the system components and the thermodynamic properties of the working fluid. This model was tested by Akintunde et al., (2006) using R12 as working fluid. The test rig used for the experiment consists of a reciprocating type compressor, $0.746 \mathrm{~kW}$ with, $32.7 \mathrm{~cm}^{2}$ cylinder; bear coil evaporator made of copper $5.588 \mathrm{~mm}$ inner diameter and $6.35 \mathrm{~mm}$ outer diameter with tube length of $14.362 \mathrm{~m}$, the condenser was of the same specifications as that of evaporator except that the length was $30.71 \mathrm{~m}$. The developed model (Akintunde, 2004a and b) was used to generate the design data presented above, using condensing temperature of $40^{\circ} \mathrm{C}$ sub cooled by $5^{\circ} \mathrm{C}$ and evaporating temperature of $-5^{\circ} \mathrm{C}$. The generated capillary tube length was $2.0 \mathrm{~m}$ which is very much closed to $2.03 \mathrm{~m}$ found in ASHRAE (2002) under the same conditions. This system was used to compare the model with an actual system using R-12 as working fluid. Under the same operational conditions, maximum absolute deviations of variable parameters - mass flow rate; condensing and evaporating temperatures and compressor speed - are within the range of 16.15 to $18.50 \%$, though most of the simulated results are within the range of 4.50 to $6.54 \%$ from an ideal cycle.

In this study, the model developed by Akintunde (2004a) was used to design a refrigeration system using thermodynamic properties of R-134a (Appendix I and II). The system was constructed out of the data generated by this model. The system was used to validate the developed model by comparing experimental results with model results under various conditions. The experimental method follows those of Jabardo et al., (2002), Akintunde et al (2006) and Khan and Zubair (1999). The objectives are to: test and check system and components performance and obtain support data for validation of computer simulation model of the refrigeration system.

\section{MATERIALS AND METHODS}

The experimental set-up is made up of: a compressor- reciprocating type, $0.746 \mathrm{~kW}$ capacity, using R134a as working fluid, with cylinder stoke volume of $32.7 \mathrm{~cm}^{2}$; evaporator and condenser, bare coil tube-in-tube serpentine copper coil. The specifications of both condenser and evaporator are shown in Table 1.

Tube-in-tube arrangement was used, to permit circulation of water to vary evaporator and condenser loads. The test sections (Condenser and Evaporator) were counter flow tube-in-tube heat exchangers with refrigerant flowing in tube and water flowing countercurrently in the annulus. The active heat transfer length for condenser is about $10 \%$ longer than that of evaporator. This will allow the removal of heat addition from compressor and some degree of subcooling. The degree of sub-cooling will still be enhanced by the flow rate of circulating water.

Table 1. Evaporator and condenser specifications.

\begin{tabular}{|c|c|c|c|}
\hline parameters & Outer diameter $(\mathrm{mm})$ & Inner diameter $(\mathrm{mm})$ & Length $(\mathrm{m})$ \\
\hline \multicolumn{4}{|c|}{ Evaporator } \\
\hline Inner tube & 9.53 & 8.01 & 3.05 \\
\hline Outer tube & 18.43 & 16.91 & 3.05 \\
\hline \multicolumn{4}{|c|}{ Condenser } \\
\hline Inner tube & 9.53 & 8.01 & 3.08 \\
\hline Outer tube & 18.43 & 16.91 & 3.08 \\
\hline
\end{tabular}


The pressure taps of the test sections are formed by drilling small holes through the tube wall. A fitting is then placed over the holes and connected to the pressure line. A $0 \mathrm{MPa}$ to $3.5 \mathrm{MPa}$ capacitance sensing gauge accurate to $\pm 4.0 \mathrm{kPa}$ measures the pressure at he test sections. T-type thermocouples calibrated to $\pm 0.15^{\circ} \mathrm{C}$ measure the fluid temperatures at the inlets and outlets of the test section. Ambient temperature was measured by a digital temperature meter with uncertainty of $\pm 0.05^{\circ} \mathrm{C}$. A schematic representation of the test rig is shown in Fig. 1.

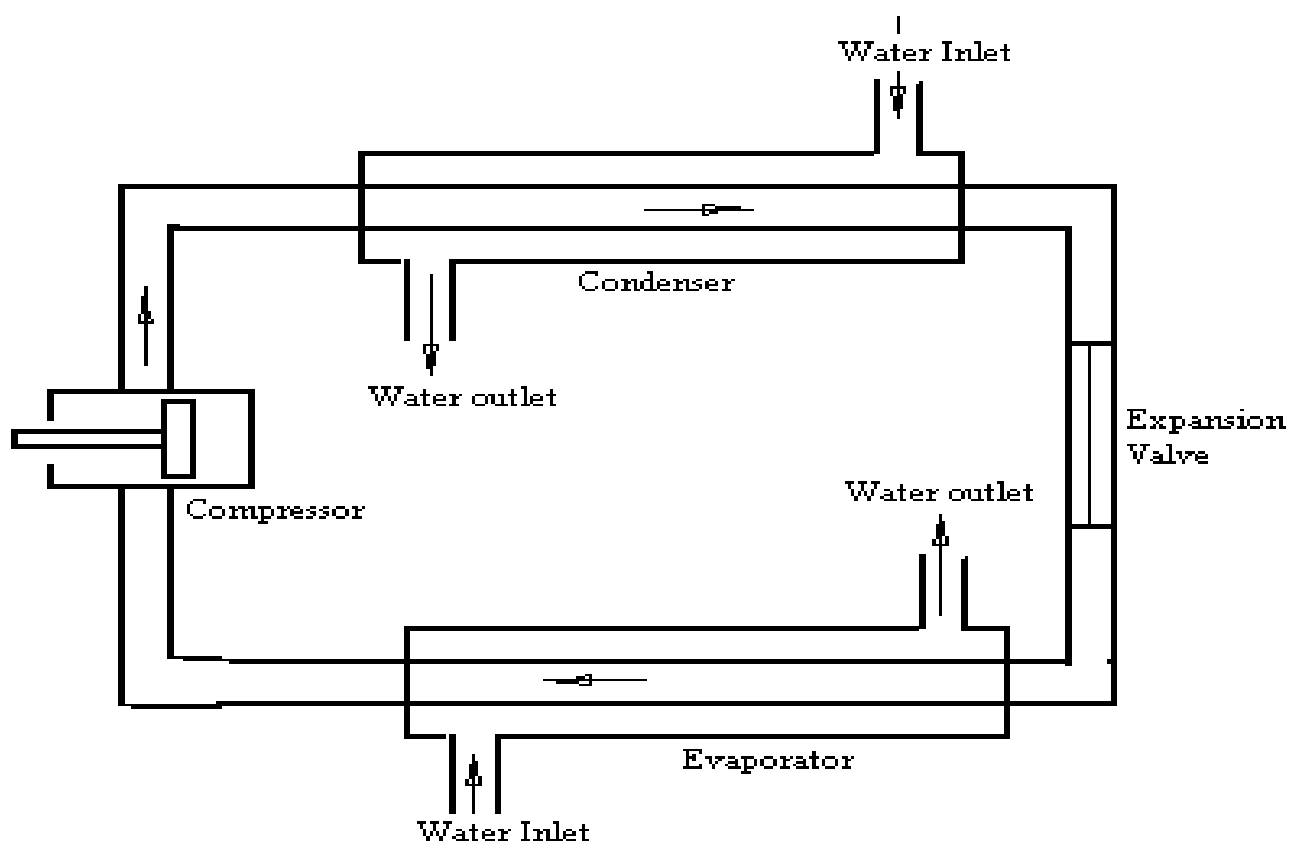

Fig. 1 A schematic representation of the test rig.

The cycle performance was evaluated through the following parameters; Cooling load $(\mathrm{Qe})$; Condensing load (Qc); Coefficient of performance (COP) and mass flow rate $(\dot{m})$. These parameters were calculated using equations (1) to (4) from Jabardo et al., (2002) and steam table from Stoecker and Jones (1982)

$$
\begin{aligned}
& Q e=\dot{m}\left(h_{e e}-h_{e i}\right) \\
& Q c=\dot{m}\left(h_{c e}-h_{c i}\right) \\
& P=\dot{m}\left(h_{c p e}-h_{c p i}\right) \\
& C O P=\frac{Q e}{P}
\end{aligned}
$$

Where: $\mathrm{h}$ is the enthalpy; and the subscripts: ee = evaporator exit; $\mathrm{ce}=$ condenser exit; cpe $=$ compressor exit; ei = evaporator inlet; $\mathrm{ci}=$ condenser inlet; cpi $=$ compressor inlet.

\section{RESULTS AND DISCUSSIONS}

Since the overall system performance is strongly influenced by operational parameters such as the evaporating and condensing temperatures, flow rates of refrigerant and the circulating water and ambient temperature, tests with the experimental rig was planned in such a way as to allow for the evaluations of their effects on COP and various operational conditions. The rig was designed using the developed model with the following inputs: evaporating temperature $-5^{\circ} \mathrm{C}$, condensing temperature $40^{\circ} \mathrm{C}$, sub-cooled to $5^{\circ} \mathrm{C}$ and an average ambient temperature of $35^{\circ} \mathrm{C}$. Data obtained from the test rig was used to assess the quality of the model relative to the experimental tests.

As reported by Lee et al., (2000), the expected charging for the capacity considered in this study should range between 800 (g) and 900 (g) of refrigerant. This is justified experimentally as shown in Fig.2. The refrigerant capacity (or the COP) increases as the charging. This trend continue till 750 (g) was charged into the system. Between $750 \mathrm{~g}$ and $900 \mathrm{~g}$ there was a partial constant after which there 
was a decrease in COP or refrigeration capacity. A charge ranged between $800 \mathrm{~g}$ and $900 \mathrm{~g}$ was used during this study.

It can be observed also in Fig. 2 that the model and the experimental data followed the same trend. The different may be associated with heat leakage. As for the effect on the mass flow rate, it has been shown in an earlier study that the refrigerant flow rate within the expected refrigerant charge is constant (Akintunde et al., 2006).

It is interesting to note that the model predicted almost a linear relationship for both refrigeration capacity (Qe) and the COP with evaporator circulating water while the experimental data Fig. 3, justified the same assertion
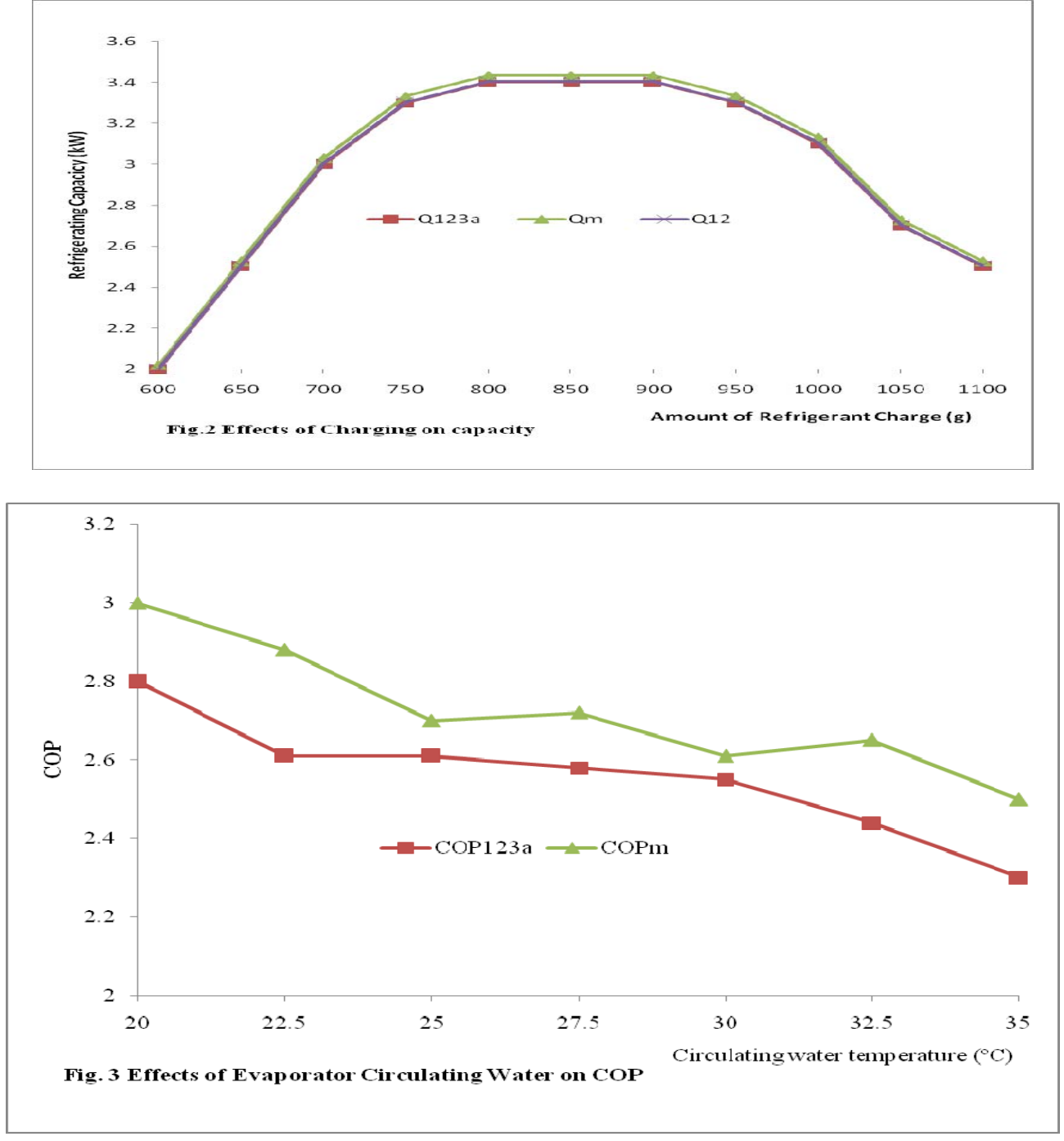

The variation between the model and the experimental data is due to heat loss, which at present it is almost impossible to prevent since there is no perfect insulation of heat. Considering the results in Fig. 3, the deviation between the model and the experimental results are a maximum of $16 \%$, for mass flow rate and $18 \%$ for COP. This shows that the model predicts the system performance to a reasonable accuracy for the indicated circulating water temperature. Correlation between circulating water temperature and the COPs gives a coefficient of $88.4 \%$ for $\mathrm{R}-134 \mathrm{a}$ and $89 \%$ for the model, the corresponding value between the two COPs is $80.7 \%$.

A similar water circulation experiment was performed on condenser. The results showed that, the evaporator pressure was relative constant while the condensing pressure increases slightly. As shown in 
Fig. 4, the refrigerating capacity (or COP) is slightly affected; it decreases as the water temperature increases. This shows that environmental effect may not have significant effect on the performance of the system especially when a balanced point is reached between the major components. The closeness of both model and experimental data showed that the model is justified. The reduction in COP occur as a result of increase in condensing pressure and hence compression work and mass flow rate. Correlation between circulating water temperature and the COPS gives a coefficient of $88.5 \%$ for R-134a and $89 \%$ for the model; the corresponding value between the two
COPs is $81 \%$. This shows that there no significant effects.

As shown in Fig. 5, a linear relationship occurs between the COPs and the degree of subcooling. Also the COPs increase with the degree of subcooling. Correlation between the degree of subcooling and the COPs gives a coefficient of $99.5 \%$ for both R-134a and the model, the corresponding value between the two COPs is $99.7 \%$. The same figures were obtained for degrees of superheat. This shows that the model is a prediction of the actual system.
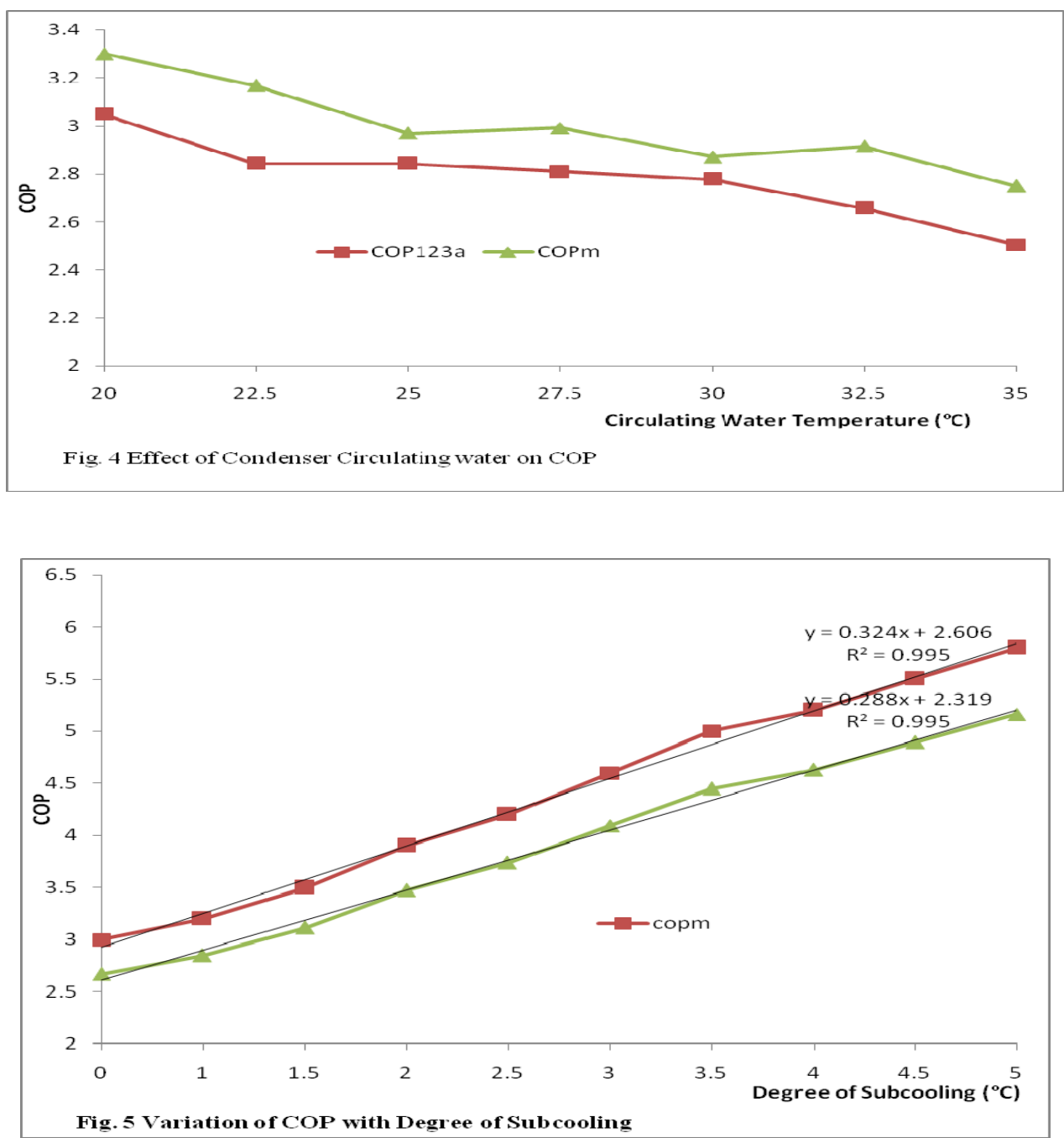

The comparison of this model with others found in the literature is shown in Fig. 6. In Fig. 6, $\mathrm{m} 1$ is ASHRAE design equation (1988), $\mathrm{m} 2$ is the present model (Akintunde, 2004a) and $\mathrm{m} 3$ is the Chen et al's equation (2000). 
Am. J. Sci. Ind. Res., 2011, 2(4): 504-510

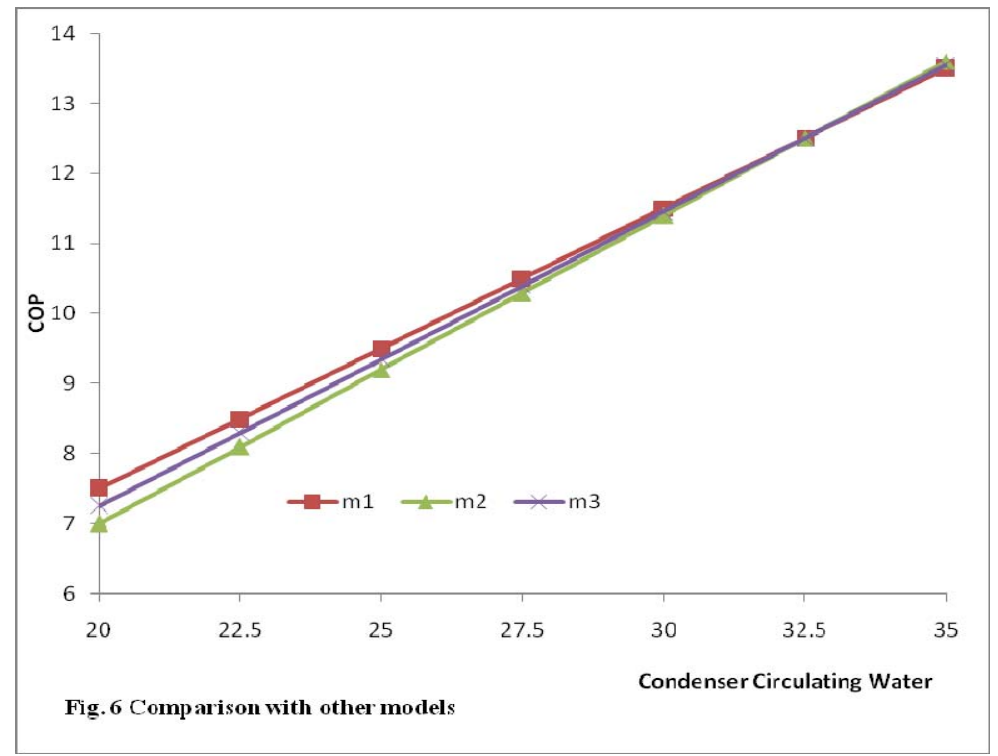

\section{CONCLUSION:}

The overall refrigeration system performance is strongly influenced by the agreement between the major components, viz: condenser, compressor, evaporator and expansion device, and the operational parameters, such as ambientcondensing- evaporating- temperatures and mass flow rate. These parameters were used in this study to validate a design model developed in a previous work by the same author. Tests results were used to assess the quality of the model by comparing the experimental results with the model predicted results. The variation of COPs, of the model and the experimental rig, with the performance parameters shows the same general trend under various investigation conditions. The $\mathrm{R}$ values (calculating using excel) of the COPs under subcooling and superheating with the degree of subcooling and superheating conditions were $80.7 \%$ and $88 \%$ respectively. While the correlations between the COPs under the same conditions were $88 \%$ and 99.9\%.

The present analysis showed that the model results are comparable to the actual system from both quantitative and qualitative points of view. Under the same operational conditions, maximum absolute deviations of the variable parameters - mass flow rate, COP and circulating water temperature, are within the range of $16 \%$. The experimental value always fall below that of model, this is as a result of experimental error such as heat leakages.

\section{ACKNOWLEDGEMENT:}

The author wish to acknowledge the Federal University of Technology, Akure (FUTA) for providing the grant for this study. The efforts of the URGC, FUTA are also acknowledged for considering the research fit for funding.

\section{REFERENCES}

Abu-Madi, M; Johns, RA and Heikal, MR (192). "The Performance of Air Conditioning in Hot Humid Environments with Non-Ozone Depleting Refrigerants". Proceedings of First UAE Conference on AirConditioning in the Gulf, pp74 - 84 .

Akintunde, MA (2004a). "Development of a Vapour Compression Refrigeration System Model Based on Balanced Points between Operating Units". PhD Thesis, Department of Mechanical Engineering, Federal university of Technology, Akure. Nigeria.

Akintunde, MA (2004b). "Theoretical Design Model for Vapour Compression Refrigeration Systems". ASME Journal. Vol. 73, No: 5, pp1 - 14.

Akintunde, MA; Adegoke, CO and Fapetu, OP (2006). Experimental Investigation of the Performance of a Design Model for Vapour Compression Refrigeration Systems". West Indian Journal of Engineering. Vol. 28 No:2, pp80 - 87 .

Akintunde, MA (2007). "Effects of Coiled Capillary Tube Pitch on Vapour Compression Refrigeration System Performance". AU Journal. Vol. 11 No. 1, pp $14-22$.

AHRAE Handbook (2002). "Refrigeration, Chapter 45.26, Adiabatic Capillary Selection Procedure".

Al-Rabgah, OM (1996). "Review and Performance Comparison among some R-12 Candidate 
Substitutes". Proceedings of First UAE Conference on Air-Conditioning in the Gulf, pp $60-73$.

Bolaji, BO (2008). "Evaluation of Environmental Friendly Refrigerants". A PhD Thesis in the Department of Mechanical Engineering, Federal University $f$ Technology, Akure, Nigeria.

Chem, SD; Cheng, YR; Liu, CH and Jwo, (2000), Simulation of Refrigeration Flowing Through Adiabatic Capillary Tubes. HVAC\$R Research. Vol. 6 No: 2, pp $101-115$.

Clark, EM (1999). "Private Communication of Refrigerants Replacement Data for Chillers in Process Use". International journal of Refrigeration. Vol. 25 No: 1, pp $193-205$.

Calm, JM (2002). "Emission and Environmental Impacts from Air-Conditioning and refrigeration Systems". International journal of Refrigeration. Vol. 25 No 2, pp $293-305$.

Crown, SW; Shapiro, HN and Pate, MB (1992). "A Comparison Study of the Thermal Performance of R12 and R-134a". Proceedings of the International Refrigeration Conference-Energy Efficiency and New Refrigerants. Vol.1 pp187 - 196.

Eckels, SJ and Tesene, BA (2003). "A Comparison of R-22, R-134a, R-410a and R-407c Condensation Performance in Smooth and Enhanced Tubes; Part I: Heat Transfer". ASHRAE Transaction, pp 428 - 441.

Eckels, SJ and Tesene, BA (2004). "A Comparison of R-22, R-134a, R-410a and R-407c Condensation Performance in Smooth and Enhanced Tubes; Part II: Pressure drop". ASHRAE Transaction, pp 442 - 452.

El-Haggar, SM; Mahmoud, NA and EISherbini, Al (1996). "Effect of Using R-134a in a Domestic Refrigerator Originally Design for R-12". Proceedings of First UAE Conference on Air-Conditioning in the Gulf, pp284 293

Hafez, MA and Rahman, F. (1999), "Environmental Effects of Ozone Depletion due to Release of Chlorofluorocarbons". Proceedings of the Symposium on the Phsing Out of CFCs, pp $266--284$.

Jabardo, JMS; Mamani, WG and lanalla, MR (2002). "Modelling and Experimental Evaluation of an Automotive Air-Conditioning System with Variable Capacity Compressor". International Journal of Refrigeration. Vol. 25 No: 8, pp1157 - 1172.

Kamei, A; Piao, CC; Sato, H and Watanabe, K (1990). "Thermodynamic Charts and Cycle Performance of FC-134a and FC-152a". ASHRAE Transaction. Vol. 96 part I, pp $144-149$.
Khan, JR and Zubair, SM (1999). "Design and Performance Evaluation of Reciprocating System". International Journal of Refrigeration. Vol. 22 No: 1, pp25 - 241.

Kim, SG; Kim, MS and Ro, ST (2002). "Experimental Investigations of the Performance of R22, R407 and R410A in Several Capillary tubes for Air-Conditioning". International journal of Refrigeration. Vol. 25 No 3 , pp $521-531$

Ko, MKW; Sze, ND; Molnar, GJ and Prather, MJ (1993). "Global Warming from Chlorofluorocarbons and their Alternatives: Time Scale of Chemistry and Climate". Journal of Atmospheric Environment. Vol. 17, No: 4, pp581 - 587 .

Kutter, W (1988). "Status and Future of Alternative Refrigerants to Chlorofluoro-carbons". Journal of Refrigeration Science and Technology. Commissions C2, D1, D2/3, E1. International Institute of Refrigeration, Paris, pp $187-194$.

Linton, JW; Snelson, WK and Hearty, PF (1989). "Performance Comparison of Refrigerants R-134a and R-12 in a Residential Exhaust Air Heat Pump". ASHRAE Transaction. Vol. 98 part I, pp 160 - 166.

Linton, JW; Snelson, WK and Hearty, PF (19892). "Effect of Condenser Liquid Subcooling on System Performance for refrigerants CFC-12, FC-134a and HFC-152a". ASHRAE Transactions. Vol. 95 art 2, p $399-404$.

Mahmoud, NA; El-Haggar, SM and Elsherbini, Al. (2002). "Performance Evaluation of an Air-Conditioning System Using R-134a as a Refrigerant". Proceedings of Arab-African Conference of Refrigeration and AirConditioning, Cairo, pp385 - 399.Statt, TG; (1990). "Potential Ozone-safe Refrigerants for Centrifugal Chillers". ASHRAE journal, Vol. 32 No: 9, pp 46 - 51 .

Sand, JR; Vineyard, EA and Nowak, RJ (1990). "Experimental Performance of Ozone-safe Alternative Refrigerants". ASHRAE Transaction Vol. 96 part 2, pp $173-181$.

Tolba, M. K., O. A. El-Kholy, E. El-Hinnawi, M. W. Holdgate, D. F. McMichael, and R. E. Munn, eds. 1992. Ozone depletion. Chapter 2 in The world environment 1972-1992. New York: Chapman and Hall.

Veneyard, EA; Sand, JR and Miller, WA (1989). "Refrigerator-Freezer Energy Testing with Alternative Refrigerants". CFCs Time of Transition Atlanta, ASHREA, pp $205-210$

Pannock, J; radermacher, R; Liu, Z and Yu, K (1994). "Evaluation of R-134a and R-152a as Working Fluids in a Domestic Refrigerator/Freezer". ASHRAE Transactions. Vol. 100 part I, pp 1344 - 1350. 